easy way to overcome this problem but it is precisely these personal contacts that are hard to cultivate because of isolation of the Third World astronomers from their counterparts in the more developed world. If there are observatories that allow photographs to be used for the price of an acknowledgment, then these invaluable resources should be listed and made known to all.

I should also mention that I believe that direct translations of foreign books into the local language may not necessarily be the right thing to do because differences in culture are significant. Geographical location is an obvious disparity and it is also true that different countries have disparate needs; therefore, the emphasis of the book should subsequently be dissimilar. A jointly written text may be more desirable, as this will allow the local author to inject the local bias of the book.

\title{
Astronomy in American Textbooks
}

Jay M. Pasachoff

Williams College, Williamstown, Massachusetts 01267, U.S.A.

Over the last dozen years, I have written textbooks on a variety of levels, starting with books for university students, proceeding to work with Naomi Pasachoff on books on the junior-high level, and, most recently, working with her and with others on an elementary-school series. I can testify that, in the United States, at least, the world of college and university texts is as different from the world of "el-hi" (elementary-high) texts as night is from day.

\section{College and University Texts}

When I began teaching astronomy, in 1972, I looked at the available texts to find one that emphasized the things that I thought were most important to teach students. Since I think students are interested by contemporary astronomy in general, and I am sure they are excited by black holes and quasars in particular, I looked for books with extensive treatments of the latter topics. To my surprise, I found none.

I nonetheless made out my course with topics distributed according to what I thought was appropriate emphasis, including whole lectures on pulsars, black holes, quasars, Mars (with Viking approaching), and so on. Eventually I had the basis of a book from my lecture notes; I had even recorded some of the lectures, though it turned out to be more difficult to transcribe them than it was to write from scratch (given that one of my major skills is typing). Eventually, I showed some of my materials to a publisher, who expressed interest - and who led me on for over a year as one editor replaced another over and over, an interesting introduction to the world of publishing. Eventually, a traveling field representative from another publisher came to my office and I showed him my material. His editor was forceful 
and active, and within a week or so I had good progress toward a contract to write a book. This book turned out to be Contemporary Astronomy, whose fourth edition has just appeared (1989). Obviously, many professors found the distribution of emphasis from topic to topic to their liking.

Contemporary Astronomy is still unique among texts in having separate chapters for the most important contemporary material, now including supernovae, neutron stars/pulsars, black holes, the Milky Way Galaxy, quasars, and the individual planets that have been visited by spacecraft. Further, I thought a major advantage was that by starting with stars, students could enter real astronomy immediately, without having to wade through many chapters of historical and positional material. Still, even with special attention to modern topics both in separate chapters and throughout, I paid and continue to pay great attention to having a fair and balanced coverage of all astronomy.

The book has appeared in many versions, including Astronomy: From the Earth to the Universe, with an increased historical emphasis and with the solar system first. Though I had originally thought that teachers could use the chapters in various orders, one professor pointed out that many students feel that difficulty correlates with page number. So now there is the "stars first" order, the "planets first" order, and a short version.

In our course at Williams, the students not only learn about general astronomy and contemporary astronomy but also do both daytime observations of the sun and nighttime observations of farther celestial objects. In addition, they do indoor laboratories with astronomical photographs and with spectroscopes. I feel strongly that a balance is necessary, and the material in my textbooks is supplemented by laboratory exercises and references in a Teachers' Guide. Students who spend too much time observing with small telescopes may not appreciate the advances of modern astronomy or comprehend that the new ideas and technology sparking those advances need support not only from individuals but also from governments and foundations. Students who spend too much time redoing methods of the past, even if they wind up with good comprehension of certain basic topics, may be lost to astronomy in particular and physical science in general when their interest is sparked by the discoveries about DNA they learn about in biology class or other contemporary aspects of various sciences.

One of the things I learned from being a textbook author is about the need to check everything. It is amazing how much I didn't know, or how much I knew that turned out to be wrong! Publishers often send drafts of textbooks to half a dozen readers, and I always sent each section to additional experts. One can learn a lot about the accuracy of a text by looking at the number and professional expertise of those acknowledged in the preface.

I also learned about economies of scale. The more copies a textbook sells, the less it can be sold for, since the publisher's receipts are, obviously, number times price. The expenses of photos and other materials, and of setting type, have to be amortized over the number of copies sold. So anything that sells more copies including, to the surprise of many, color plates - means that the book can be sold 
more cheaply. A major problem now is that the used-book business has become very well organized, with whole classloads of books shipped around the country. These books are bought from students very cheaply, but by the time profits are taken by the middlemen and the bookstores, the price to students is not too much lower than that of new books. And not only the authors' royalty but also money to the publishers is not paid. Sales for the second year of a book plummet, and publishers are less willing to invest the effort needed for quality books. Allowing bookstores to sell used books in this way seems shortsighted. And any professor who allows a used-book salesman to buy the sample copies that publishers send out is causing harm.

I am continually reminded how nice it is that astronomy is my field, for so much new material is constantly available. It is interesting to see how many new discoveries have been made, often requiring new chapters, from one edition to the next.

\section{Elementary, Junior-High, and High-School Texts}

Whereas for college and university students, publishers print what the author writes (after suitable editing and review), "el-hi" texts are committee efforts. The author certainly plays a role in defining the book, but the in-house editors at the el-hi publishers have final say about all aspects of the book.

In 1980, my wife (Naomi Pasachoff) and I signed on with Scott, Foresman and Co., one of the largest el-hi publishers, known to Americans of my generation as the publishers of the "Dick and Jane" juggernaut. The number of editors involved with the junior-high texts in Earth Science and Physical Science that we wrote together (and my wife does the lion's share) with a third author they assigned, $T$. Cooney, approached 10. But the number was justified by the eventual sales; perhaps $2,000,000$ students a year take junior-high science, and our books have for each of the last five years sold about 200,000 copies.

Still, it is a continual struggle to see that the material that appears is correct and well put. Our original manuscript passes through so many hands and revisions by non-astronomers that errors often creep in. Every time the manuscript or proof goes by us, we make it correct, but sometimes we wind up correcting the same point several times. Apparently the authors of competing junior-high texts aren't as compulsive as we are about corrections, or, because they aren't astronomers, weren't as knowledgeable in the first place, because I often find egregious errors in these other texts. I would like to see the accuracy and up-to-date nature of our texts be major selling points, but the el-hi publishers seem to advertise only on the basis of "readability" and seem to minimize the fact that a "college professor" in a discipline (that is, not a professor of education) is associated with the project.

We have heard several times at this Colloquium that students don't understand such basic matters as tides and seasons. Perhaps part of the problem is that their textbooks may have explained them unclearly or incorrectly. Because of all the hands the material passes through, it is difficult even for my wife and me to get 
correct explanations into our own books. If only we scientists can think of a way - perhaps by convincing statewide adoption committees, who often must approve textbooks on this level - to require accuracy, the texts students use would be much improved. It would be good if scientists in each discipline were asked by such adoption committees to comment on the accuracy of the texts being considered. Perhaps you can volunteer to advise your local school board.

Whatever projects are being developed for the future, there are millions of students taking school science courses now. Thus one can exert a tremendous influence by participating in ongoing textbook projects. We have, in our books, succeeded in enlarging the quota of astronomy taught to hundreds of thousands of junior-high students each year; since each book is often used for five years in a given school, our books are equivalent to 1 million student-users each year, or a 5 -million-user total so far. Our junior-high effort was successful enough that not only have second editions of Earth Science and Physical Science appeared (1990) but also we have been included in an "author team" for Discover Science (1990), a series of 7 books for grades Kindergarten and first through sixth. All these books are lavishly laid out and illustrated in full color, and represent major investments for the publisher.

We hope that others join us in trying to spread astronomy and accurate science through the schools. More scientists participating as authors would be great. And more scientists advising their local, county, or state adoption committees that accurate and up-to-date science texts are necessary would be very helpful to today's students.

\section{Conclusions}

It is important to be clear about our goals when teaching. For example, is it more important to teach about the advance of knowledge in astronomy during the current era or is it more important to teach about basics like phases and seasons? Or what balance should be struck? The question of what we should teach goes, of course, with the question of what students should learn. My own evaluation is that it is important for students of all ages to know, and therefore for us to teach, about both modern advances in astronomy and about the general basics. If I had to choose, though, I would choose contemporary astronomy, for some students might be attracted to astronomy as majors as a result of exciting advances. Further, even non-major students become citizens and voters, and it is important for them to understand that astronomy continually progresses. If their understanding were limited to basics, they might feel that astronomy had been worked out long ago, that new investments for astronomical research are not necessary, and that there would be no point for them to consider going into astronomy or voting for politicians who support research. On the other hand, though a gap in their understanding of basics should be plugged, students with such gaps who understood the vibrancy of contemporary astronomy would nonetheless feel that astronomy was exciting and that it was worth supporting.

In essence, the astronomy non-major survey course can be an "astronomy 
appreciation" course, similar to "music appreciation" courses. It should not dwell excessively on conceptual basics, just as it would be a pity for a music appreciation course to limit itself to understanding chords without ever hearing a symphony. Similarly, elementary-school and high-school courses should also include the exciting results of modern astronomy in addition to providing astronomical basics.

Another analogy might be with teaching English. University professors of English (or, in non-English-speaking countries, of the respective dominant languages) are teachers of literature. They assume that grammar is known; they are sometimes willing to correct students' grammatical deficiencies, but those corrections are not their main job. These professors are to teach Shakespeare (or, in France, Victor Hugo) and the contemporary novel, rather than to teach punctuation. Even in schools during the lower grades, good English teachers teach about poetry and prose, and do not limit themselves to grammar. Analogously, we astronomers must bring our students to see the wonders of the universe in the view of our latest understandings as demonstrated by the glories of contemporary research.

\title{
Textbook Panel Presentation - IAU Colloquium 105
}

\author{
R. Robert Robbins, \\ Department of Astronomy, University of Texas, Austin, Texas 78712, U.S.A.
}

You might be somewhat surprised by the presentations [as delivered] so far, in that there has been relatively little discussion of pedagogical matters (e.g., what should be the content of a text and what should be its order and manner of presentation). It seems that rather personal factors are in the foreground of everyone's thinking. But I think that is probably inevitable, because the process of writing a textbook is not only a huge undertaking that comes to dominate the life of the author, but it is also an endeavor that places the author directly at the interface between the idealistic world of education and the very practical world of economics as dictated by the realities of the publishing markets. In addition, a textbook has a strong effect on an astronomy class. It has been suggested that an important reason why so many educational research studies fail to come to a definite conclusion is that the textbook is such a dominant influence that it swamps all the other factors!

We have already seen that much of the astronomy teaching in the United States is in courses for non-science majors. These courses generate huge enrollments; at my institution, we teach some 7000 students per year (about 20,000 credit hours). It is these enrollments that make it possible for commercial publishers to make a profit on a textbook, because every student is expected to buy a copy of the book. And of course we see the evidence of this - a great proliferation of non-mathematical texts for non-science majors, in English.

Where it is not profitable to publish a book, the books do not appear. Note the shortage of books for astronomy majors, even in English. The market is just too 